involved in the growth-regulating activity of this acid. In his studies on anti-auxins, Prof. Thimann has found that, under certain conditions, 3-methylindole can depress the activity of 3 -indolylacetic acid. The effect is not shown with low concentrations of the acid, indicating that competitive antagonism is not involved and that 3-methylindole is not an antiauxin. Prof. Thimann has concluded from further experiments that $2: 4$-dichloroanisole, claimed to be an anti-auxin by Bonner, is likewise a growth inhibitor only. Studies with 3-indolylacetonitrile were also described by Prof. Thimann. Evidence was presented which indicates that, in tests where the nitrile shows activity, such activity depends upon its conversion to 3 -indolylacetic acid within the plant tissue. Prof. H. Burström (Lund), in a comprehensive physiological paper, made an attempt to define growth activity. In particular, he dealt with auxin and anti-auxin activity, the type of antagonism shown only by external growth substances, the disturbance of geotropic responses, and toxicity. The paper, which was illustrated throughout by detailed reference to the growth effects obtained with specific compounds, focused attention on the complex interplay of physiological processes which may be concerned in promoting the various types of growth response.

R. L. WAIN

\section{CHEMICAL PROCESSES AND CHEMICAL ENGINEERING TECHNIQUES}

$\mathrm{T}$

HE first chemical plant exhibition to be held in Great Britain since 1936 was housed at Olympia, London, during September 3-17 in conjunction with the annual engineering, marine and welding exhibitions. The Institution of Chemical Engineers, together with the Chemical Engineering Group of the Society of Chemical Industry, marked the occasion by holding a chemical engineering conference during the five days commencing September 7 .

The meetings were avowedly general in nature, being designed to support the plant exhibition, and the theme of the entire conference could be described as one of 'materials and methods'. Perhaps the focal point of the meetings was that held under the chairmanship of Mr. Stanley Robson, at which the implications of recent reports upon American practice ("Chemical Apparatus in the U.S.A." by the Organization for European Economic Co-operation, and "Heavy Chemicals" by the Anglo-American Council on Productivity) were considered.

Sir Harold Hartley and Mr. J. Grange Moore initiated a wide discussion in which the most preeminent views were that industry needs more chemical engineers, but should also make better use of those it has. Prof. M. B. Donald warned the profession that it would find itself starved of entrants unless something were done to reduce the serious shortage of science teachers in grammar schools.

Around this central theme, covering the whole scope of chemical engineering, other papers were placed dealing with more specific developments in processes and techniques. Among these were contributions dealing with some unusual materials of construction. Thus, carbon and graphite (Mr. A. W. Morrison), tantalum and zirconium (Dr. G. L. Miller) and plastic materials (Mr. Verney Evans) were presented, and their special properties and applica- tions in the chemical ind ustries illustrated. Much interest was shown in thesr topics; and the importance of constructional materia s, in that their development is often the limiting fac uor in the application of new processes, was stressed by more than one speaker.

The remaining papers presented to the conference dealt with chemical processes and chemical engineering techniques. Two interesting examples of specialist design and operation resulting from the penetration of chemical engineering fundamentals into two specific processes were provided by papers on milk processing plant (Mr. J. E. F. Renton) and formaldehyde production (Mr. K. Nickels).

The increasing use of chlorine throughout the industry made of timely interest a paper on developments in the production of chlorine in mercury cells (Mr. L. R. Thomas), particularly as the author drew many useful comparisons between alternative cell designs. A paper on advances in evaporation, with particular reference to the concentration of heatsensitive liquids (Mr. B. N. Reavell), provided further examples of the application of a general technique to a specific problem. This provoked a lively discussion by its treatment of the economics of multipleeffect evaporation, as well as by a description of lesser-known systems, such as low-temperature elimbing-film machines operating on the heat-pump principle.

Of more general interest was a review of developments in distillation since 1940 (Mr. G. A. Dummett). Although necessarily very compressed, the paper made an assessment of the important progress which has been made during the past thirteen years in fundamental physical data, in theoretical design methods and in practical industrial equipment.

In ranging from the very general comparison of the practice of chemical engineering in Great Britain and the United States to the wide distribution of a particular operation, this brief report discusses in a re-arranged order the papers of the conference and not in the order in which they were read.

\section{T. K. Ross}

\section{BRITISH PHARMACEUTICAL CONFERENCE, 1953}

$T$

HE ninetieth British Pharmaceutical Conference was opened at Grosvenor House, London, on August 31, and more than six hundred pharmacists attended. The range of topics covered in the scientific sessions illustrates the extensive development of pharmaceutical research.

Fresh interests in the constituents of plants were demonstrated by several workers who have applied. new methods of analysis. The quantitative estimation of the ergot alkaloids has been achieved by partition chromatography on cellulose columns, and colorimetric assay of the fractions shows that recoveries of pure individual alkaloids are consistent. The constituents of digitalis tinctures have been investigated, no correlation having been found between the potency of frogs to the glycosides and the intensity of the colour reaction. Other workers have applied paperpartition chromatography to the separation of the tropane alkaloids, their estimations being carried out by use of the Vitali-Morin reaction. The chromatographic method has been particularly useful in estimating the hyoscine and hyoscyamine content of Datura sanguinea. 
From experimental work on the biogenesis of the tropane alkaloids some speculations have been made, and the results appear to indicate that the product of synthesis is related to the site of synthesis. The histochemical evidence for alkaloid production in meristematic tissues has been corroborated, and two other workers directed attention towards the root as the locus of alkaloid synthesis. Reciprocal grafts between tetraploid and diploid Datura stramonium have been made, and it was suggested that the genetical nature of the stock determines the alkaloidal content of scion and stock. In branch chimæras the tetraploid branch is richer in alkaloid than the diploid branch growing on the same root.

One curious fact has come to light as a result of a study of the anthraquinone glycosides of cascara, namely, that galenical preparations containing glycosides in amounts similar to those found in the crude drug are only half as active. The use of boiling water and autoclaving was stated to be a more efficient method of producing the dry extract of cascara than extraction with cold water ; apparently, evaporation of the percolate under reduced pressure does not enhance the potency of the final product.

The use of dihydrostreptomycin and of penicillin as a mixed preparation raises an assay problem, and it has been established that the success of any micro. biological method must depend on the absence of interference by dihydrostreptomycin. A further paper related to the origin of stimulation zones on penicillin assay plates, and attributed the cause, in part, to additional nutrients having diffused from the inhibition zones.

A method was described using small groups of guinea pigs for demonstrating the prolonged action of globin insulin and protamine zinc insulin. The guinea pig was recommended as a satisfactory test animal, whereas this demonstration cannot be carried out with the rabbit. Another paper compared the efficiency of two official pyrogen tests, and suggested that the further use of rabbits, which had once been used in a test in which pyrogen had been found, should be forbidden. The maximum degree of restraint which may be imposed on the rabbits should be specified and electrical thermometers should be used.

The work of several contributors was focused on the stability of some pharmaceutical preparations. Methods of assessing the chemical stability of procaine benzyl-penicillin in aqueous media were described. A study of different batches of vitamin $B_{12}$ injections has shown that differences in potency are caused by exposure to daylight. Although copper is known to affect the stability of aneurine hydrochloride solution, it was pointed out that the same effect is greatly diminished in dry powders when stored at room temperature over long periods. The problem of assessing emulsion stability was considered, and the breakdown has been investigated over the temperature range $4-85^{\circ} \mathrm{C}$. It is considered that globule-size frequency analysis yields a reliable picture of the internal state of the emulsion. Elevated temperature was proposed as an artificial breakdown stress for the evaluation of emulsion stability.

Pharmacological research on some synthetic drugs was reported, and one substance has proved of value as a substitute for $p$-amino-salicylic acid, appearing to delay the emergence of streptomycin resistance. A structural analogue of hydrocortisone has been prepared and found to inhibit the glyconeo-genetic activity of cortisone acetate in adrenalectomized rats.
Further research has been carried out on bacterial survival in systems of low moisture content, and oils suitable for use in 'sterility tests' have been ingeniously prepared. A limiting viable count technique has been modified. Also reported was the fact that, by using soluble surface-active agents in small amounts, cotton dressings will retain their absorbency better than the conventional type. Three papers read at the Conference made a useful contribution to the problem of evaluating antacids, and a further paper described a rapid method of determining calcium and magnesium by titration.

For many years pharmacists have been 'glass conscious' and aware of the necessity of controlling its quality and characteristics when used as containers for pharmaceutical preparations. With the latter comment one paper was introduced as a contribution to the symposium session, which dealt with the pharmaceutical aspects of glass and rubber. Experiences with containers and closures in the pharmaceutical industry were also discussed.

S. B. Challen

\section{MOVEMENT OF POSTGRADUATE SCIENCE STUDENTS}

MONG the activities of the British Council which $A$ are of direct interest to science none is more important than its encouragement of the movement of scientists, by bringing to Great Britain scientists, both postgraduates for purposes of advanced study or research, and more senior people to visit their opposite numbers, and by arranging for British scientists to pay lecturing or advisory visits overseas. This flow of scientists is, of course, only part of such movements, and because the funds available to the British Council for these purposes are limited, it is essential that they should be deployed in those directions where the need is greatest. This cannot be done effectively without a reasonably accurate knowledge of the flow of scientists promoted by other sources. Various publications indicate the awards available; but hitherto there have been no statistics showing the extent and characteristics of the flow which actually occurs.

For this reason the Executive Committee of the British Council in November 1951 agreed to the appointment of a working party of representatives of the Council itself, the Royal Society, the Department of Scientific and Industrial Research and the Medical and the Agricultural Research Councils, to review broadly and report on existing facilities for the movement of scientists, so as to arrive at a measure of the present scale of such activities, and to explore the need for any further co-ordination. The working party consisted of Sir Alfred Egerton, Dr. D. C. Martin, Dr. Alexander King, Mr. W. G. Alexander, Dr. F. H. K. Green (who withdrew later since in his opinion the examination was unlikely to yield data of use to medicine) and Sir Kenneth Loch, and it selected the calendar year 1951 as a sample period, deciding also to limit the investigation to the movement of graduate scientists whose journeys were made for the purpose of either advanced study or research. Assistance was sought from British universities, official bodies, trust funds and other organizations known to have an interest in this type of movement. For each individual information was collected on the professional status 